\title{
Distribution of arsenic in an argillaceous sample using sequential chemical extractions: application to the Hydrogeological Experimental Site of Poitiers (HESP)
}

\author{
Rana Mhanna ${ }^{1,{ }^{*}}$, Aude Naveau ${ }^{1}$, Maité Bueno ${ }^{3}$, Laurent Caner $^{1}$, and Joseph Bassil ${ }^{2}$ \\ ${ }^{1}$ CNRS, Université de Poitiers, 86073 Poitiers CEDEX 9, France \\ ${ }^{2}$ L2GE, Lebanese University, Faculty of Sciences, Fanar, Matn, Lebanon \\ ${ }^{3} \mathrm{CNRS} /$ Université Pau \& Pays de l'Adour, 64053 Pau Cedex 9, France
}

\begin{abstract}
Arsenic mobility and transport into groundwater is highly dependent on its chemical distribution in sediments. In this study, a combination of sequential extraction and mineralogical investigation by $\mathrm{X}$ ray diffraction on a sample collected from the hydrogeological experiment site of Poitiers (France) was tested to evaluate and predict the mobility of arsenic in different conditions. Results showed that the highest fraction of As $(\sim 35 \%)$ was released by $25 \%$ nitric acid however this fraction is poorly mobile under natural chemical conditions due to its high stability. Exchangeable As ( 14\%) and As bound to iron and aluminium oxides $(\sim 12 \%)$ exhibited a significant fraction that could be of high concern in case of change in the ionic composition and redox conditions, respectively. Soluble fraction comprised only $1 \%$ of As which was in accordance with the composition of groundwater in the site.
\end{abstract}

\section{Introduction}

Arsenic (As) is a metalloid that has gained an increasing attention in the last decades due to the growing awareness of its toxic effect on human health [1]. High exposure to As, mainly via drinking water, is associated with various types of cancer, cardiovascular, neurological and other types of diseases [2]. According to the European standards, arsenic contamination of ground water occurs when its total concentration exceeds the value of 10 $\mu \mathrm{g} / \mathrm{L}$ [3]. There are many sources of arsenic in waterbodies, some are geogenic such as mobilization from sediments while others are anthropogenic such as mining and agricultural runoff. The toxicity of arsenic relies in its known mobility under a wide range of $\mathrm{pH}$ and redox conditions. In sediments, arsenic can be linked to several solid phases that might be solubilized under certain changes in groundwater conditions causing the release of the associated arsenic through desorption or dissolution [4]. Hence, in order to predict arsenic's mobility and bioavailability, it is of great importance to determine its distribution and chemical associations in sediments rather than only measuring its total concentration [5].

* Corresponding author: rana.mhanna@univ-poitiers.fr 
Several methods have been used for the determination of the chemical forms of trace elements such as X-ray absorption near edge structure (XANES) and extended X-ray absorption fine structure (EXAFS), but the low detection limit required for arsenic analysis renders their use inconvenient [6]. Hence, sequential extraction schemes were employed as effective predictors of the impact of contaminants on the environment. In this paper, a protocol for arsenic fractionation was developed and applied on a sediment containing a significant concentration of arsenic $(\sim 22 \mathrm{mg} / \mathrm{Kg})$. The obtained results from sequential extraction experiments were discussed considering complementary mineralogical investigation.

\section{Sequential extraction}

Sequential extraction is a method used for solid phase partitioning that comprehensively investigate contaminant's distribution in soils and sediments [7]. It requires the use of several extraction solutions having increasing chemical strength to target different components.

Sequential extraction is a relatively simple method that gives a better idea on the behavior of contaminants under different conditions which can improve the understanding of factors controlling them. In addition, it provides detailed information about the mobility and thus the transport of the studied contaminants into waterbodies [8]. However, some of its drawbacks might include the redistribution of the analyte among different phases and the formation of new precipitates during extraction, re-adsorption of the analyte, poor selectivity of some reagents and possible overestimation of some phases [6].

Several extraction schemes for arsenic fractionation were developed, with a huge discrepancy among number of steps, extraction solutions and conditions utilized. Nevertheless, the common feature among the different studies is that fractions are operationally defined. Arsenic can be associated with several solid phases such as iron and aluminium oxides, carbonated minerals, pyritic materials, clay minerals and organic matter [9]. Hence, it is of great importance to target these solid constituents in order to release the associated arsenic.

\section{Materials and methods}

\subsection{Study area}

Sediment used in this study was collected from the hydrogeological experimental site of Poitiers (HESP). This site is located $2 \mathrm{~km}$ south west of Poitiers city in France and consists of an area of 10 ha where 37 wells were cored through the Middle Jurassic (Dogger) and infraLias aquifers separated by the marls of the supra-Lias. HESP is an operational scientific platform that hosts national and international scientific projects in the aim of developing new approaches in the characterization and modelling of groundwater flows [10].

The studied sediment was of black argillaceous nature, collected from C5 well through a non-destructive drilling in 2012 in the Dogger aquifer of the HESP at a depth between 66 and $71 \mathrm{~m}$ and corresponds to karst filling materials dated from the Upper Cretaceous (for more details on sediment sampling and preservation, reader can refer to articles [10] and [11]). This sediment was particularly chosen due to its enrichment in arsenic ( 22 ppm) even though the value of arsenic in the water of the correlated site was below the detection limit. 


\subsection{Methodology}

Sediment used in this study is a powder obtained by grinding and sieving at $200 \mu \mathrm{m}$. During extraction experiments, $0.6 \mathrm{~g}$ of C5 sediment was added to a $50 \mathrm{~mL}$ centrifuge tube along with $20 \mathrm{~mL}$ of extraction solutions. Tubes were agitated using a magnetic stirrer at a speed of $350 \mathrm{rpm}$ then centrifuged at a speed of $14000 \mathrm{rpm}$ for 10 mins (i.e. $21900 \mathrm{~g}$ ). After that, supernatant was recovered and the subsequent extraction solution was added to the same solid residue. The residue obtained from the extraction experiments was oven-dried for 1 week at $105{ }^{\circ} \mathrm{C}$ and ground with an agate mortar and pestle. In order to identify the change in the mineralogy of the sediment, comparison between X-ray diffraction patterns before and after extraction was conducted and shown in Figure 1. Powder samples were analyzed through X-ray diffraction using Philips Panalytical X'pert Pro apparatus equipped with Copper radiation of wavelength $1.5418 \AA$, scanning from $3-65^{\circ} 2 \theta$. Elemental analysis of C5 sediment was conducted at SARM laboratory (CRPG-CNRS, Nancy, France) and is summarized in Table 1. The used protocol was adapted through modifications of the previous protocols $[7,10,12]$. A summary of the applied protocol is shown in Table 2. Aliquot from each fraction was analysed for arsenic using inductively coupled plasma mass spectrometry (ICP-MS; Agilent 7500ce). Residue value was calculated from the difference between the total arsenic and the sum of the extracted fractions.

Table 1. Chemical composition of C5 sediment.

\begin{tabular}{cccccccccccc}
\hline Major Elements & $\mathrm{SiO}_{2}$ & $\mathrm{Al}_{2} \mathbf{O}_{3}$ & $\mathbf{L O I}$ & $\mathrm{Fe}_{2} \mathbf{O}_{3}$ & $\mathrm{TiO}_{2}$ & $\mathbf{C a O}$ & $\mathbf{M g O}$ & $\mathbf{K}_{2} \mathbf{O}$ & $\mathbf{N a}_{2} \mathbf{O}$ & $\mathbf{C o r g}$ & $\mathbf{S}$ total \\
& $38.27 \%$ & $28.64 \%$ & $22.34 \%$ & $1.72 \%$ & $1.72 \%$ & $1.01 \%$ & $0.29 \%$ & $0.07 \%$ & $0.03 \%$ & $5.35 \%$ & $0.54 \%$
\end{tabular}

Minor Elements As (mg/Kg) Se (mg/Kg) Cs (mg/Kg) Rb (mg/Kg) Sr (mg/Kg) Pb (mg/Kg) Th (mg/Kg) U (mg/Kg) REE (mg/Kg)

\begin{tabular}{lllllllll}
22.42 & 6.29 & 1.39 & 4.59 & 20.86 & 56.60 & 24.33 & 14.43 & 812.78 \\
\hline
\end{tabular}

Table 2. Sequential Extraction Protocol.

\begin{tabular}{|c|c|c|c|c|}
\hline \multicolumn{2}{|c|}{ Fraction Targeted Phase } & \multirow{2}{*}{$\begin{array}{l}\text { Extractant } \\
\text { Deionized water }\end{array}$} & \multirow{2}{*}{$\frac{\mathrm{pH}}{6.5}$} & \multirow{2}{*}{$\frac{\text { Extraction Conditions }}{2 \text { hrs, room temperature }}$} \\
\hline F1 & Soluble As & & & \\
\hline $\mathrm{F} 2$ & Exchangeable As & $0.05 \mathrm{M} \mathrm{HNa}_{2} \mathrm{O}_{4} \mathrm{P} / \mathrm{H}_{2} \mathrm{NaO}_{4} \mathrm{P} \cdot \mathrm{H}_{2} \mathrm{O}$ & 7 & $2 \mathrm{hrs}$, room temperature \\
\hline $\mathrm{F} 4$ & $\mathrm{Fe}$ and $\mathrm{Al}$ Oxides bound $\mathrm{As}$ & $0.2 \mathrm{M}\left(\mathrm{NH}_{4}\right)_{2} \mathrm{C}_{2} \mathrm{O}_{4} \cdot \mathrm{H}_{2} \mathrm{O} / \mathrm{C}_{2} \mathrm{H}_{2} \mathrm{O}_{4} \cdot \mathrm{H}_{2} \mathrm{O}$ & 3 & 2 hrs, dark, room temperature \\
\hline F5 & Organic Matter bound As & $0.1 \mathrm{M} \mathrm{NaOH}$ & 13 & $24 \mathrm{hrs}$, room temperature \\
\hline
\end{tabular}

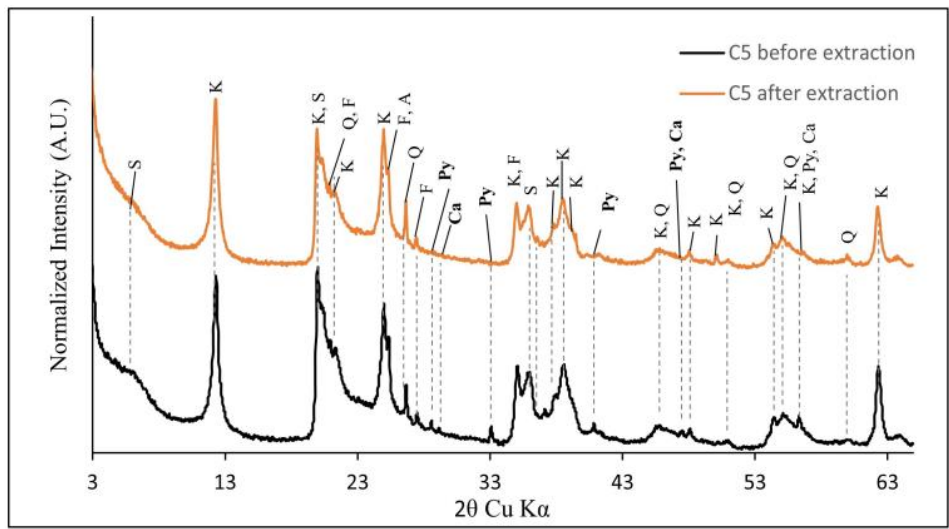

Fig. 1. XRD patterns before and after extraction of C5 sediment (A: Anatase, Ca: Calcite, F: Feldspar, K: Kaolinite, Py: Pyrite, Q: Quartz, S: Smectite). 


\section{Results and Discussion}

Arsenic extracted in the soluble fraction (F1) was relatively low with a value of $1.2 \pm 0.1 \%$ (Fig. 2), which was in agreement with water analysis of the water site which didn't show any detectable amount of soluble As. A much higher amount was extracted in the exchangeable fraction (F2) with a value of $13.8 \pm 1.2 \%$. This fraction is mobilized by anion exchange between arsenate and phosphate ions due to the similarity of their electron configuration however, the smaller size and higher charge density of phosphate causes the desorption of arsenate [13]. Exchangeable arsenic is an easily mobilized fraction, hence a significant amount of As can be directly released under a change of ionic composition or $\mathrm{pH}$ [8]. A value of $9.2 \pm 0.8 \%$ of total As was extracted with acetate buffer (F3) and a post extraction analysis showed $100 \%$ release of calcium ions. Considering the low amount of calcium in the sediment (Table $1, \mathrm{CaO}=1.1 \%$ ) with the very small peak of calcite in the diffractogram of the raw sample (Fig. 1), two approaches can be assumed. The first suggests that a significant fraction of As was associated with calcite, given that all calcium was released and calcite peaks disappeared after extraction. The second suggests that the major fraction released in this step was due to decomplexation of specifically adsorbed As on the sediment surface by the two carboxylic groups of acetate [7].

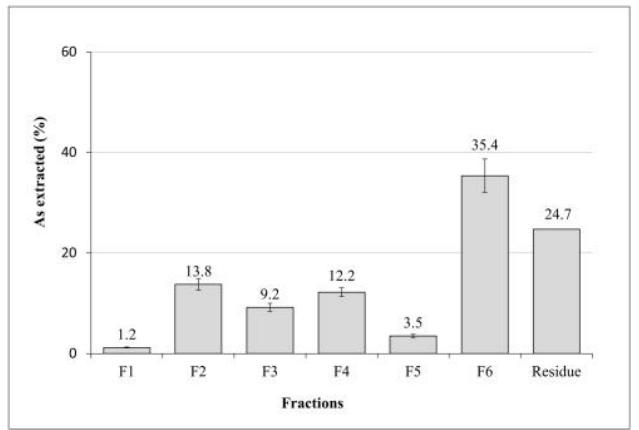

Fig. 2. Sequentially extracted fractions of arsenic from C5 sediment. F1: soluble As; F2: exchangeable As; F3: specifically sorbed and carbonate bound As; F4: iron and aluminium oxide bound As; F5: organic matter bound As; F6: pyritic As.

Extraction with oxalate buffer (F4) contributed to $12.2 \pm 0.9 \%$ of total As. This fraction comprises amorphous and poorly crystallized iron and aluminium oxides that are mobilized under reducing conditions [14]. Elements that are soluble with $\mathrm{NaOH}$ (F5) are called alkaline soluble species which are normally associated with humic-like organic matter [10]. Taking into account the significant organic content of this sediment (Table $1, \mathrm{C}_{\mathrm{org}}=5.68$ $\%)$, it can be assumed that the released As in this step (3.5 $\pm 0.3 \%)$ was associated with alkaline soluble organic substances. The highest extracted As was released with nitric acid (F6, 35.4 $\pm 3.3 \%$ ). The main proportion of the released arsenic could be associated with pyrite considering its high ability to scavenge arsenic and its high dissolution in $25 \%$ $\mathrm{HNO}_{3}$ as reported in previous studies [7, 12]. Further evidence is provided by the comparison of the XRD profiles before and after extraction (Fig. 2) which revealed the disappearance of pyrite peak mainly at $33^{\circ} 2 \theta$. However, this fraction can be mainly mobilized under conditions that causes the weathering of pyrite [12].

\section{Conclusion}

Results of the distribution of arsenic in C5 sediment by sequential extraction experiments showed that $\sim 35 \%$ of As was released by nitric acid; however, this fraction is considered 
relatively stable and immobile under natural chemical conditions. On the other hand, the exchangeable fraction $(\sim 14 \%)$ comprises ions that are most readily available into the environment [8] and thus can be of high concern. The fraction released by oxalate buffer $(\sim 12 \%)$ includes species that are moderately reducible and normally unstable under anoxic conditions. The low soluble fraction obtained is in agreement with the undetectable arsenic content in the water of the HESP wells.

\section{References}

1. E. Lombi, et al., Water Air Soil Pollut, 124, 319-332 (2000)

2. Y.S. Hong, et al., J Prev Med Public Heal, 47, 245-252 (2014)

3. K. Henke, Arsenic: Environmental Chemistry, Health Threats and Waste Treatment, John Wiley \& Sons, New York, 545-568 (2009)

4. K.A. Hudson-Edwards, et al., TrAC - Trends Anal Chem, 23, 745-752 (2004)

5. X. Wan, et al., Chemosphere, 178, 402-410 (2017)

6. J.R. Bacon, C.M. Davidson, Analyst, 133, 25-46 (2008)

7. A. Tessier, et al., Anal Chem, 51, 844-851 (1979)

8. A.V. Filgueiras, et al., J Env Monit, 4, 823-857 (2002)

9. M.B. Javed, et al., Anal Chim Acta, 787, 102-110 (2013)

10. J. Bassil, et al., Env Sci Pollut Res, 23, 9598-9613 (2016)

11. J. Bassil, et al., C R Geoscience, 348 598-608 (2016)

12. E.J. Kim, et al., Env Pollu, 186, 29-35 (2014)

13. W.W. Wenzel, et al., Anal Chim Acta, 436, 309-323 (2001)

14. R. Larios, et al., Anal Bioanal Chem, 402, 2909-2921 (2012) 